\title{
Analysis of Neonatal Radiographic Examination Entrance Surface Dose (ESD) and Scattering Dose (SD)
}

\author{
Ari Murtanto ${ }^{1}$, Guntur Winarno ${ }^{2}$, Yulfania Rahmates ${ }^{3}$, Novi Azman ${ }^{4}$ \\ ${ }^{1,2,3}$ Physics, ${ }^{4}$ Electrical Engineering, Engineering and Science Faculty, Universitas Nasional, Jakarta, Indonesia. \\ Corresponding Author: Novi Azman
}

DOI: https://doi.org/10.52403/ijrr.20220228

\begin{abstract}
Diagnostic radiology is also used in the assessment and treatment of neonates. Radiographic examinations are often used to assess the development of the lungs and internal organs of the abdomen with medical abnormalities in infants. This study aims to analyze the dose of surface radiation in infants and the dose of scattered radiation during a radiographic examination in the Neonatal Intensive Care room at a hospital in East Jakarta. The research method used is experimental based on quantitative data processing to determine the surface dose received by the baby and the scattered radiation dose during radiographic examination. The measuring instrument used is the Thermoluminescence Dosimeter (TLD) for the surface radiation dose and the Survey meter for the scattered radiation dose. The dose of surface radiation obtained from 6 infant patients was still above the recommended dose. The dose ratio obtained is between 1.9-3.36 times the UNSCEAR dose. Meanwhile, the scattered radiation dose produced is below the Dose Limit Value set by BAPETEN.
\end{abstract}

Keywords: Entrance Surface Dose (ESD), Scattering Dose (SD), Survey meter, Thermoluminescence Dosimeter (TLD)

\section{INTRODUCTION}

The use of X-rays as diagnostic radiology plays a very important role in the diagnosis process, which in its use must be based on the ALARA (as low as reasonably achievable) principle. It is without exception used in the assessment and treatment of neonates requiring intensive care. It is often necessary to perform a radiographic examination which depends on the baby's birth weight, gestational age and health problems [1]-[4].

In addition to providing benefits, radiation also poses a harmful threat to humans. According to the United Nations Scientific Committee on the Effects of Atomic Radiation (UNSCEAR), the likelihood of long-term effects (delayed effects) from radiation exposure for children is 2-3 times higher than for adults. It is also necessary to be aware of the dangers posed, especially by exposure to scattered radiation. Radiographic examination of organs that have a high thickness and atomic number will require high $\mathrm{X}$-ray energy as well, so that the scattered radiation is also high [5]-[8].

\section{LITERATURE REVIEW Radiation Dose Level}

In a radiological examination, the dose received by the whole body varies, and the maximum dose occurs in the skin receiving the primary radiation beam. This skin surface dose is called the Entrance Surface Dose (ESD) [9]-[12]. The ESD value can be determined in 2 ways, namely direct measurement using a Thermoluminescence Dosimeter (TLD) and indirect measurement using the radiation exposure parameters of the X-ray machine 
output $(\mathrm{kV}, \mathrm{mAs}$, irradiation field area, HVL, and patient thickness) [6], [13], [14]. The recommended dose value of the United Nations Scientific Committee on the Effects of Atomic Radiation (UNSCEAR) in 2008 which is an institution with a mandate to assess doses. Table 1 is the surface radiation dose for Thorax and Abdomen examination aged 0-1 years [15]-[17]. Table 1 shows the doses used based on various sources.

Table 1: Surface radiation dose from various sources

\begin{tabular}{|l|l|l|l|}
\hline No & $\begin{array}{l}\text { Dosage by various } \\
\text { sources }\end{array}$ & $\begin{array}{l}\text { Infant } \\
\text { Thorax } \\
\text { (mGy) }\end{array}$ & $\begin{array}{l}\text { Abdomen } \\
\text { (mGy) }\end{array}$ \\
\hline 1 & UNSCEAR 2008 & 0.06 & 0.11 \\
\hline 2 & In European Comission & 0.045 & 0.44 \\
\hline 3 & Hospitals in Madrid & 0.04 & 0.09 \\
\hline
\end{tabular}

Calculation of radiation dose (D) received by TLD is done using the equation (1).

$$
D=T L D \text { Reading Result }(n C) \times F_{k}(m G y / n C)
$$

In an exposure to X-ray radiation, of course, scattered radiation will be produced. Scattered radiation depends on the quality of the main beam, determined by the magnitude of $\mathrm{kVp}$. When the $\mathrm{X}$-ray machine is operated, a small amount of radiation leaks out (leakage radiation) that comes out of the surroundings of the X-ray tube, and the X-ray beam that is useful for producing the image that strikes the patient is then scattered in all directions as scattered radiation. It can be said that there is scatter radiation which consists of leakage radiation, scattered radiation, and backscattered radiation.

BAPETEN has stipulated in the Regulation of the head of BAPETEN No. 4 of 2013 concerning Radiation Protection and Safety in the Utilization of Nuclear Energy Article 23, the Dose Limit Value (DLV) for community members is $1 \mathrm{mSv}$ per year. In contrast to individual dosimeters, surveymeter can display measurement results directly when exposed to radiation. This tool can be used to measure radiation exposure in all terrains and locations. The measurement method applied is current mode, so the value displayed is the radiation intensity value. This value is converted into a dose scale with units of X-ray/hour.

\section{MATERIALS \& METHODS}

The research design used in this study was experimental based on quantitative data processing to determine the surface dose received by the infant and the scattering radiation dose during radiographic examination.

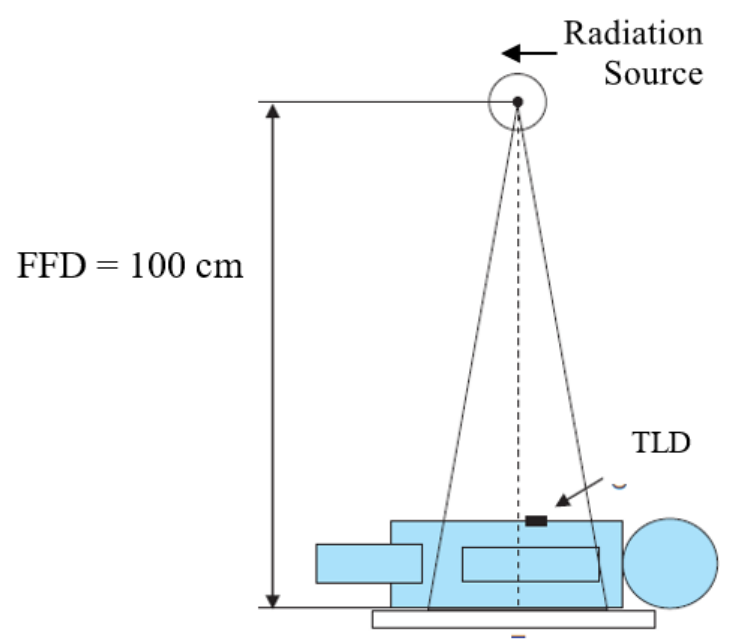

Figure 1: Direct measurement of surface dose to infants using TLD-100

Measurements were carried out as shown in Figure 1 directly on infant patients in the Neonatal Intensive Care room. TLD is placed right in the middle between the Thorax and Abdomen, namely in the Procesus Xhypoideus, collecting data for 6 infant patients. With parameters FFD (Focus Film Distance) $=100 \mathrm{~cm}$ and exposure factor $=44 \mathrm{kV}$ and $4 \mathrm{mAs}$.

Scattered radiation measurements were carried out using a Surveymeter in the Neonatal Intensive Care Room. The measurement scheme is carried out as shown in Figure 2.

The " $X$ " box is where the radiographic examination is carried out. One examination was carried out for one scatter radiation dose measurement site. The places to be measured are the right, left and in front of the $\mathrm{X}$ box with a distance of $1 \mathrm{~m}$ using a Surveymeter. Data collection 5 times on each side to be measured. 


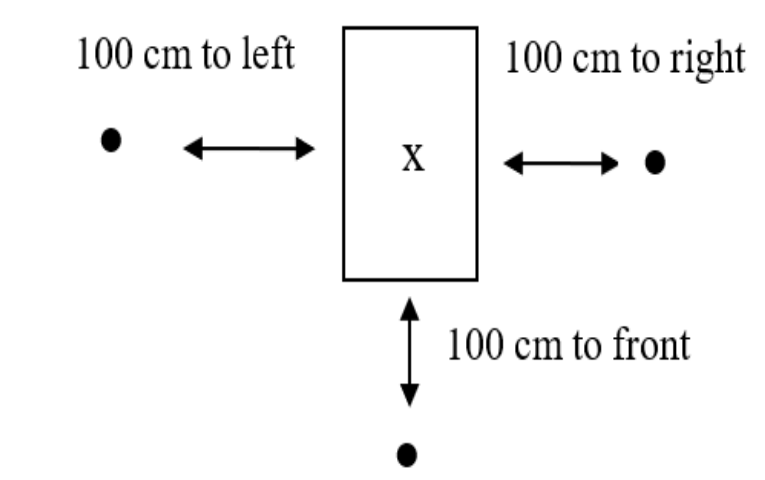

Figure 2: Scattered radiation dose measurement scheme using Surveymeter

\section{RESULTS \& DISCUSSIONS \\ Surface Absorption Dose}

The results of these measurements were compared with doses determined by UNSCEAR, the city of Madrid and the European Commission. The following is Figure 3. a graph between the thickness of the baby's abdomen and the radiation dose obtained and the radiation dose determined by UNSCEAR, the city of Madrid, and the European Commission.

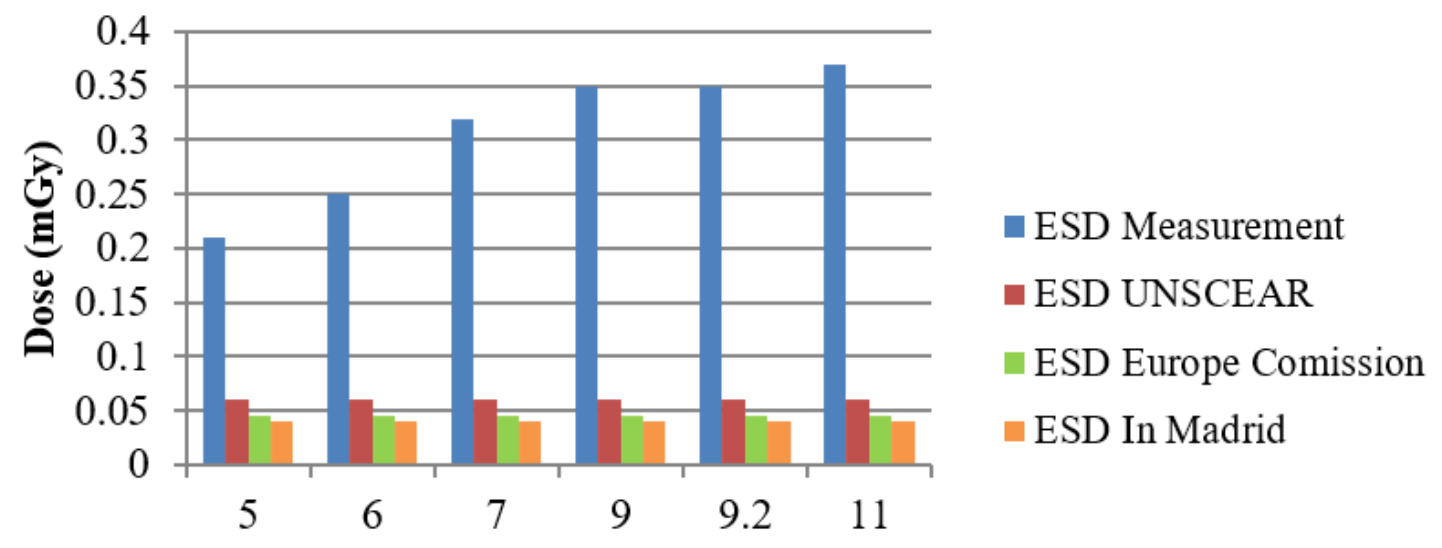

Abdomen Thickness (cm)

Figure 3: Graph of the relationship between infant patient thickness and surface radiation dose based on UNSCEAR, City of Madrid and the European Commission

The ratio of the measurement dose to the dose set by UNSCEAR from the lowest to the highest are.

$$
\begin{aligned}
& \frac{D_{\text {measurement }}}{D_{U N S C E A R}}=\frac{0,21}{0,06}=3,5 \mathrm{mGy} \\
& \frac{D_{\text {measurement }}}{D_{U N S C E A R}}=\frac{0,37}{0,06}=6,167 \mathrm{mGy}
\end{aligned}
$$

The ratio of the measurement dose to the European Commission dose from lowest to highest are.

$$
\begin{aligned}
& \frac{D_{\text {measurement }}}{D_{U N S C E A R}}=\frac{0,21}{0,045}=4,67 \mathrm{mGy} \\
& \frac{D_{\text {measurement }}}{D_{U N S C E A R}}=\frac{0,37}{0,045}=8,22 \mathrm{mGy}
\end{aligned}
$$

Comparison of the measurement dose with the dose in the City of Madrid from the lowest to the highest are.

$$
\begin{aligned}
& \frac{D_{\text {measurement }}}{D_{U N S C E A R}}=\frac{0,21}{0,04}=5,25 \mathrm{mGy} \\
& \frac{D_{\text {measurement }}}{D_{U N S C E A R}}=\frac{0,37}{0,04}=9,25 \mathrm{mGy}
\end{aligned}
$$

\section{Scattered Radiation Dose}

Measurements were made at 3 (three) points on the right, left, and front of the X-ray tube, each measuring 5 (five) times. The measurement results of the scattered radiation dose have been multiplied by a calibration factor of 1.16 $\mathrm{Sv} / \mathrm{h}$. Based on observations regarding the recommended scattered radiation dose in the Dose Limit Value (DLV) listed in the Regulation of the head of BAPETEN No. 4 of 2013 concerning Radiation Protection and Safety in the Utilization of Nuclear Energy for members of the public, namely 1 $\mathrm{mSv} /$ year. The measurement results are converted into $\mathrm{mSv} / \mathrm{year}$, so $1 \mathrm{mSv}=1000$ Sv and 1 year $=8760$ hours. 
The scattered radiation dose on the left becomes.

$$
0,016 \mu \mathrm{Sv} /{ }_{h}=\frac{0,016 \times 8760 \mathrm{mSv}}{1000 \text { years }}=0,14 \mathrm{mSv} / \text { year }
$$

The scattered radiation dose on the right becomes.

$$
0,016 \mu \mathrm{Sv} / h=\frac{0,014 \times 8760 \mathrm{mSv}}{1000 \text { years }}=0,12 \mathrm{mSv} / \text { year }
$$

The scattered radiation dose on the front becomes.

$$
0,016 \mu \mathrm{Sv} / h=\frac{0,016 \times 8760 \mathrm{mSv}}{1000 \text { years }}=0,14 \mathrm{mSv} / \text { year }
$$

The measurement results that have been converted are analyzed with the dose limit values set by BAPETEN in Table 2 .

\begin{tabular}{ccccc}
\multicolumn{2}{c}{ Table 2: Analysis of Suitability with Dose Limit Value } \\
\hline \multirow{2}{*}{$\begin{array}{c}\text { Radiation } \\
\text { location }\end{array}$} & $\begin{array}{c}\text { Average } \\
(\mu \mathrm{Sv} / \mathrm{h})\end{array}$ & $\begin{array}{c}\text { Average } \\
(\mathrm{mSv} / \mathrm{year})\end{array}$ & $\begin{array}{c}\text { DLV } \\
\text { (mSv/year) }\end{array}$ & Remarks \\
\hline Left & 0.016 & 0.14 & 1 & Below DLV \\
Right & 0.014 & 0.12 & 1 & Below DLV \\
Front & 0.016 & 0.14 & 1 & Below DLV \\
\hline
\end{tabular}

Observations/Results of your study should be written in this section along with tables/charts/figures etc. write serial numbers and appropriate heading/title of tables and legend/caption of figures.

\section{CONCLUSION}

The radiation dose received by the baby in the Neonatal Intensive Care Room at Hospital "B" was still above the dose recommended by UNSCEAR. The ratio of the obtained dose to the UNSCEAR dose is between $3.5-8.2$ times the UNSCEAR dose. The measurement of the scattered radiation dose resulting from the examination at Hospital "B" is still below the Dose Limit Value set by BAPETEN. Measurements were made using a surveymeter placed at $100 \mathrm{~cm}$. It was safe to do without a shield because it was still below the Dose Limit Value.

\section{Acknowledgement: None}

\section{Conflict of Interest: None}

\section{Source of Funding: None}

\section{REFERENCES}

1. G. R. Schooler, J. P. Cravero, and M. J. Callahan. Assessing and conveying risks and benefits of imaging in neonates using ionizing radiation and sedation/anesthesia, Pediatr. Radiol., pp. 1-6, 2021.

2. M. J. Park, S. S. Kim, G. Y. Park, and H. S. Hong. Radiation exposure of very-lowbirth-weight infants in neonatal intensive care units in Korea, Radioprotection, vol. 53, no. 4, pp. 279-286, 2018.

3. T. Olgar et al. Radiation exposure to premature infants in a neonatal intensive care unit in Turkey, Korean J. Radiol., vol. 9, no. 5, pp. 416-419, 2008.

4. S. C. Cakir et al. Radiation Exposure in the Neonatal Intensive Care Unit in Newborns and Staff, Am. J. Perinatol., 2021.

5. Bouaoun, L. Ben-Omrane, and A. Hammou. Radiation doses and risks to neonates undergoing radiographic examinations in intensive care units in Tunisia, Internafional J. Cancer Ther. Oncol. 3 342, vol. 347, 2015.

6. Aliasgharzadeh, D. Shahbazi-Gahrouei, and F. Aminolroayaei. Radiation cancer risk from doses to newborn infants hospitalized in neonatal intensive care units in children hospitals of Isfahan province, Int. J. Radiat. Res., vol. 16, no. 1, pp. 117-122, 2018.

7. N. Azman, F. Yasman, E. R. Nugroho, and E. Sinaga. Design of Automatic Phototherapy System for Neonatal Hyperbilirubinemia, Int. J. Recent Technol. Eng., 2019.

8. N. Azman, I. T. Anggraini, S. R. Wicaksono, and F. Djauhari. Design of temperature and humidity monitoring baby incubator based on internet of things, Int. J. Adv. Trends Comput. Sci. Eng., vol. 9, no. 5, pp. 8390-8396, 2020.

9. L. C. Santos, F. R. Lima, P. H. Andrade, V. H. Silva, and J. W. Vieira. Dosimetry in diagnostic radiology using synthetic bone micromatrices, in Proceedings of XI Regional Congress on Radiation and Nuclear Safety, Regional Congress of the 

dose $(S D)$.

International Radiation Protection Association (IRPA)), 2018.

10. K. M. Kanal. Patient dosimetry in diagnostic radiology, J. Med. Phys., vol. 43, no. suppl. 1, p. 1, 2018.

11. F. Pernicka and I. D. McLean. Dosimetry in diagnostic radiology: an international code of practice. International Atomic Energy Agency, 2007.

12. C.L. Chapple. Patient dosimetry in diagnostic radiology-some practical considerations in an NHS region, 2020.

13. S. J. Noh, T. J. Park, and Y. K. Lim. A Study on the Radiation Performance Testing and Evaluation Technology for Survey Meter Based on International Standards, J. Radiat. Ind., vol. 15, no. 2, pp. 99-106, 2021.

14. D. Celeste, A. Curioni, A. Fazzi, M. Silari, and V. Varoli. B-RAD: a radiation survey meter for operation in intense magnetic fields, J. Instrum., vol. 14, no. 05, p. T05007, 2019.
15. G. Alzen and G. Benz-Bohm. Radiation protection in pediatric radiology, Dtsch. Arztebl. Int., vol. 108, no. 24, p. 407, 2011.

16. United Nations Scientific Committee on the Effects of Atomic Radiation. Sources and Effects of Ionizing Radiation: Report to the General Assembly with Scientific Annexes. Volume 2. Annex D. Health Effects Due to Radiation from the Chernobyl Accident (advanced Copy). UN, 2011.

17. Furlow. Radiation protection in pediatric imaging, Radiol. Technol., vol. 82, no. 5, pp. 421-439, 2011.

How to cite this article: Ari Murtanto, Guntur Winarno, Yulfania Rahmates et.al. Analysis of neonatal radiographic examination entrance surface dose (ESD) and scattering dose (SD). International Journal of Research and Review. 2022; 9(2): 199-203. DOI: https://doi.org/ 10.52403/ijrr.20220228 